\title{
Poly(ethylene glycol) or Poly(ethylene oxide)? \\ Magnitude of end-group Contribution to the Partitioning of Ethylene Oxide Oligomers and Polymers between Water and Organic Phases
}

\author{
Marcos Spitzer, Edvaldo Sabadini and Watson Loh* \\ Instituto de Química, Universidade Estadual de Campinas, CP 6154, 13083-970, Campinas - SP, Brazil \\ A partição de $\mathrm{PEO}$ de água para $\mathrm{CH}_{2} \mathrm{Cl}_{2}$ e $\mathrm{CHCl}_{3}$ aumenta com a sua massa molar, até se tornar \\ constante em torno de $3000 \mathrm{~g} \mathrm{~mol}^{-1}$. Estes resultados revelam que a partição de PEO é bastante \\ sensível à contribuição dos grupos hidroxila, sugerindo a transição de caráter poliglicol para poliéter
} em torno de $3000 \mathrm{~g} \mathrm{~mol}^{-1}$.

PEO partitioning from water to $\mathrm{CH}_{2} \mathrm{Cl}_{2}$ and $\mathrm{CHCl}_{3}$ increases with its molar mass, leveling off at ca. $3000 \mathrm{~g} \mathrm{~mol}^{-1}$. Such a behaviour is related to PEO end-group contributions, suggesting a polyglycol to polyether transition at ca. $3000 \mathrm{~g} \mathrm{~mol}^{-1}$.

Keywords: poly(ethylene glycol), poly(ethylene oxide), polymer partitioning, polymer fractionation, biphasic systems, end-group contribution

\section{Introduction}

Ethylene oxide oligomers and polymers (hereafter referred to as PEO) are amongst the most commonly used substances in pharmaceutical and other industrial formulations. Depending on the oligomer/polymer molar mass, they have been called poly(ethylene glycol)s or poly(ethylene oxide)s, the former applied to smaller ones to suggest a glycolic chemical nature attributed to significant contributions from their hydroxyl end-groups. Just for guidance, catalogues from some common chemical companies place this transition between molar mass of 3350 or $10000 \mathrm{~g} \mathrm{~mol}^{-1} .^{1}$ More than a nomenclature issue, this end-group contribution may have important implications, as already stressed in relation to PEO solubility ${ }^{2}$ and miscibility in blends. ${ }^{3}$ In general, it is assumed that endgroup effects become less important, and, eventually, insignificant, as polymer molar mass increases, but no clear discrimination of this transition region for PEO has been presented yet.

Most PEO applications depend on its high water solubility, a feature that has been related to a precise fitting of the ethylene oxide units into liquid water structure ${ }^{4}$ (for instance, poly(methylene oxide) and poly(propylene oxide) are considerably less soluble in water), in addition

* e-mail: wloh@iqm.unicamp.br to favourable contributions from its hydroxyl end-groups. Despite this high aqueous solubility, there is a classical statement (found in Bailey's textbook ${ }^{5}$ ) that PEO may be extracted from water to organic solvents, that has been ascribed to an entropy increase due to the loss of polymer chain helicity upon transfer from water to the apolar phase. Polymer partitioning is a key issue in the mechanism of formation of liquid biphasic systems (both aqueous and organic), as well as an important step in fractionation procedures. For PEO, it is of great importance when extended to biological systems, given its use, for instance, in cell fusion, where a key step has been proposed to be PEO interaction / partitioning at the biological membrane. ${ }^{6}$

In the last years, we have investigated PEO solution behaviour in both aqueous ${ }^{7}$ and organic ${ }^{8-10}$ biphasic systems, and shown that polymer solvation makes an important contribution to the driving forces controlling the formation of such systems. ${ }^{70}$ Hence, continuing this line of investigation, we report in this communication partitioning studies in three water/organic biphase systems, as a function of PEO molar mass, aiming at factoring out the individual contributions of ethylene oxide and hydroxyl groups.

\section{Results and Discussion}

Table 1 shows the partition coefficients $(\mathrm{K})$ measured at $298 \mathrm{~K}$ for some PEO and PEO-dimethyl ethers in biphasic 
systems containing water and dichloromethane, chloroform or chlorobenzene. ${ }^{11}$ These data were obtained at $c a .8$ $10 \%$ total polymer concentrations, where polymerpolymer interactions or entanglements may be present, especially for PEO of higher molecular weights. Partition coefficients for PEO 3350 determined at different polymer contents $(1,5$ and $10 \%)$ led to essentially the same $\mathrm{K}$ values, suggesting that contribution from these interactions may be insignificant.

Table 1. Partition coefficients, expressed as the ratio of ethylene oxide (EO) mole fraction in the organic phase to that in the aqueous phase, for some PEO in aqueous/organic biphasic systems.

\begin{tabular}{lccc}
\hline $\begin{array}{l}\text { Oligomer } \\
\text { or Polymer }\end{array}$ & Dichloromethane & Chloroform & Chlorobenzene \\
\hline PEO 200 & 0.248 & 0.41 & - \\
PEO 300 & 0.63 & 1.13 & 0.03 \\
PEO 400 & 1.14 & 2.0 & - \\
PEO 600 & 2.46 & 4.44 & - \\
PEO 1000 & 9.3 & 18.7 & 0.013 \\
PEO 3350 & 175 & 132 & 0.03 \\
PEO 35000 & 332 & 197 & 0.05 \\
PEO 500 & 68 & 92 & - \\
dimethyl ether & & 279 & - \\
PEO 2000 & 209 & & \\
dimethyl ether & & & \\
\hline
\end{tabular}

It is clear from these data that these organic solvents behave differently, since with chlorobenzene, PEO partitioning is always favoured into water, whereas for the other two, this preference shifts as PEO molar mass varies. The first behaviour may be ascribed to a less efficient PEO solvation by chlorobenzene, in comparison with water, which is not surprising considering the lower solubility of the polymer in this solvent. Such a more efficient $\mathrm{PEO}$ solvation by $\mathrm{CH}_{2} \mathrm{Cl}_{2}$ and $\mathrm{CHCl}_{3}$ may be attributed to their hydrogen bonding donating capability, which has already been stressed as an important feature related to PEO solubility. ${ }^{2}$

As for the behaviour observed in systems containing $\mathrm{CH}_{2} \mathrm{Cl}_{2}$ and $\mathrm{CHCl}_{3}$, the trend of increasing $\mathrm{K}$ values with the increase of PEO molar mass agrees with the proposition that end-group effects, which should act favouring its partitioning into water, become less important. A clearer picture of these trends, including data for more polymers, is presented in Figure 1. In general, the same tendency is observed for partitioning into both chloroform and dichloromethane/water systems, with increasing $\mathrm{K}$ values for increasing molar mass, until levelling off at $c a .3350 \mathrm{~g}$ $\mathrm{mol}^{-1}$. The only difference is the slightly higher partition coefficients with chloroform for lower molar mass, a sequence opposite to that observed for PEO solubility. ${ }^{10}$

The first striking point that arises from these data is that PEO begins to prefer the organic phase at quite low molar

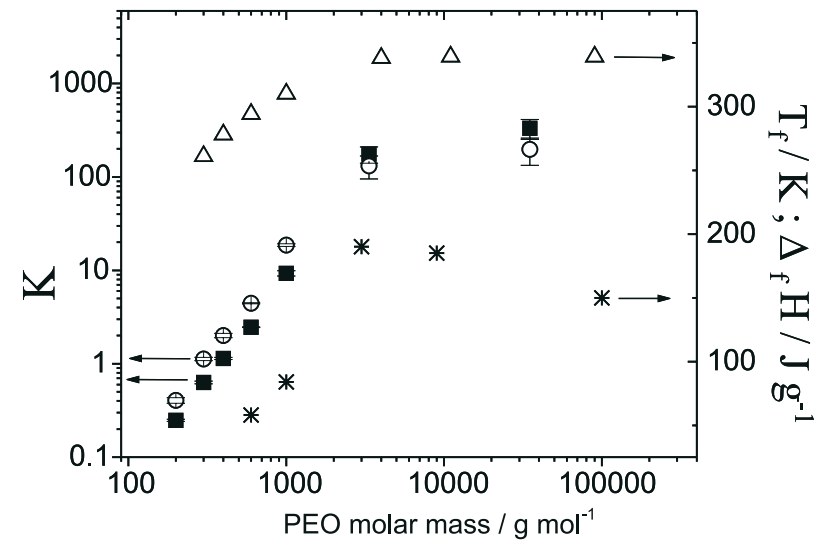

Figure 1. Partition coefficients, expressed on EO mole fraction basis, in aqueous/organic biphasic systems as a function of PEO molar mass: (O) PEO in $\mathrm{H}_{2} \mathrm{O} / \mathrm{CHCl}_{3}$, (ם) PEO in $\mathrm{H}_{2} \mathrm{O} / \mathrm{CH}_{2} \mathrm{Cl}_{2},(\Delta)$ PEO melting point ${ }^{12,13}$ and (*) PEO enthalpy of fusion. ${ }^{13}$

mass, $300 \mathrm{~g} \mathrm{~mol}^{-1}$ for chloroform and $400 \mathrm{~g} \mathrm{~mol}^{-1}$ for dichloromethane, indicating that its apolar nature (polyether) starts to prevail even for oligomers most commonly referred to as glycols. This fact may have important implications when analysing PEO partitioning in other systems. It is important, however, that this behaviour does not occur with chlorobenzene (preliminary investigations indicate that PEO also partitions predominantly into water in the presence of ethyl acetate and THF). At this point it is not clear which solvent property controls PEO partitioning, but it would be interesting to assess, for instance, the partitioning behaviour exhibited with solvents usually assumed to mimic biological membranes. ${ }^{14}$

Methylation of PEO end-groups produces a remarkable increase of $\mathrm{K}$ values, as shown in Table 1, which is well above any estimated increase due to the addition of two methyl groups (even if assumed as two extra EO units). Such an increase confirms that $-\mathrm{OH}$ groups still contribute significantly, favouring PEO partitioning into water even above the 300-400 $\mathrm{g} \mathrm{mol}^{-1}$ range.

Another interesting point revealed in Figure 1 is that, unlike the partitioning of homologous series between aqueous/organic phases, the increment (sometimes referred to as $\Delta \Delta_{\mathrm{t}} \mathrm{G}$ ) in Gibbs energy of transfer ( where $\Delta_{\mathrm{t}} \mathrm{G}=-\mathrm{RT} \ln \mathrm{K}$ ) per EO subunit is not constant, but decreases as the polymer chain length increases, eventually vanishing, when the plateau is reached. For molar mass below $1000 \mathrm{~g} \mathrm{~mol}^{-1}$, this increment per ethylene oxide unit varies between $c a .-1$ and $-0.4 \mathrm{~kJ} \mathrm{~mol}^{-1}$, much smaller than values for the transfer of one methylene unit between water and organic solvents (usually in the range of $-3 \mathrm{~kJ} \mathrm{~mol}^{-1}$ ). ${ }^{15}$ The fact that a plateau is reached is also important since it reveals that, for polymers above the molar mass range of 3350-35000 g mol-1, increase in PEO molar mass does not change significantly their solvation 
properties. Interestingly, a similar behaviour is displayed by other PEO properties, as its melting point and enthalpy of fusion, such as shown in Figure 1. Since all comparisons are made on a monomer basis, those findings suggest that, above this molar mass range, upon addition of more EO units to the polymer chain, the average contribution of its end-groups becomes insignificant, a feature associated with the polyglycol to polyether transition, as previously described. Sakellariou and co-workers ${ }^{2}$ also found a two-step variation for the hydrogen-bonding basicity contribution to PEO solvation, but with a change at molar mass around $1000 \mathrm{~g} \mathrm{~mol}^{-1}$.

Such changes in polymer properties would be felt not only in solution properties, like partitioning, but also in other physical properties related to polymer-polymer interaction, as in the case of melting presented in Figure 1.

Another consequence of this plateau is that fractionation of PEO by molar mass in such biphasic systems would not be effective above $3350 \mathrm{~g} \mathrm{~mol}^{-1}$. On the other hand, for PEO below $1000 \mathrm{~g} \mathrm{~mol}^{-1}$, Figure 1 provides a means of estimating selectivity factors for PEO fractionation. For instance, the ratio of partition coefficients for PEO 300 and 400 (difference of $2 \mathrm{EO}$ units) in water/chloroform equals 2.

Regarding the reasons that drive PEO preferential partitioning into $\mathrm{CH}_{2} \mathrm{Cl}_{2}$ and $\mathrm{CHCl}_{3}$ phases at higher molar mass, ongoing calorimetric investigations point out that, in all cases studied, PEO transfer from water to organic phases is an endothermic process and, hence, controlled by an entropy increase that overcomes the enthalpic contribution. ${ }^{16}$ However, at the moment, it is not possible to ascribe the reasons for this entropic control.

In conclusion, addressing the question of the molar mass at which poly(ethylene glycol) becomes poly (ethylene oxide), i. e., at which a polyether does not feel any contribution from its end-groups, it certainly does not occur below $2000 \mathrm{~g} \mathrm{~mol}^{-1}$, where a significant increase in $\mathrm{K}$ value was still observed upon dimethylation. The plateau observed in Figure 1, also displayed by other PEO physical-chemical properties, supports the idea that this transition may be placed between 3000 and $35000 \mathrm{~g} \mathrm{~mol}^{-1}$. Nevertheless, if the question focuses on the molar mass at which PEO partitioning shifts its preference from the aqueous to the organic phase, the present communication reveals that, for solvents like chloroform and dichloromethane, it occurs at 300-400 $\mathrm{g} \mathrm{mol}^{-1}$.

\section{Acknowledgements}

The Brazilian Agencies FAPESP (research grant and scholarship to M.S.) and CNPq (research fellowship to W.L.) are gratefully acknowledged for their support.

\section{References}

1. Aldrich Catalogue, 2000/2001 and Fluka Catalogue, 1997/ 1998.

2. Sakellariou, P.; Abraham, M.H.; Whiting, G.S.; Colloid Polym. Sci. 1994, 272, 872.

3. Wolf, B.A.; Schuch, W.; Makromol. Chem. 1981, 182, 1801.

4. Kjellander, R.; Florin, E.; J. Chem. Soc. Faraday Trans. 1 1981, 77, 2053.

5. Bailey Jr, F.E.; Koleske, J.V. In Poly(ethylene oxide), Academic Press, N. York, 1976, p. 117.

6. Lentz, B.R.; Lee, J.K.; Mol. Membr. Biol. 1999, 16, 279.

7. da Silva, L.H.M.; Loh, W.; J. Phys. Chem. B 2000, 104, 10069.

8. da Silva, L.H.M.; Loh, W.; Chem. Commun. 1998, 787.

9. da Rosa, R.G.; Martinelli, L.; da Silva, L.H.M.; Loh, W.; Chem. Commun. 2000, 33.

10. Spitzer, M.; da Silva, L.H.M.; Loh, W.; J. Braz. Chem. Soc. 2000, 11, 375 .

11. The following oligomers and polymers were used as received in the present study (with supplier): PEO 200 (Sigma), 300 (Aldrich), 400 (Sigma), 600 (Riedel), 1000 (Sigma), 3350 (Fluka), 35000 (Fluka), and dimethyl PEO of nominal molar mass 500 and $2000 \mathrm{~g} \mathrm{~mol}^{-1}$ (Aldrich). Organic solvents of best purity available were kept over molecular sieves, after being treated as follows: $\mathrm{CH}_{2} \mathrm{Cl}_{2}$ was refluxed over $\mathrm{CaCl}_{2}$ for $24 \mathrm{~h}$ and distilled under nitrogen; $\mathrm{CHCl}_{3}$ and chlorobenzene were washed with water, dried with $\mathrm{K}_{2} \mathrm{CO}_{3}$, refluxed with $\mathrm{P}_{2} \mathrm{O}_{5}$ and $\mathrm{CaCl}_{2}$ for $2 \mathrm{~h}$ and distilled. Doubly distilled water was used throughout. Partition coefficients were obtained by dry-weight (solvent removal at temperatures below $60^{\circ} \mathrm{C}$ for $24 \mathrm{~h}$ ), after equilibration for, at least, three days in a temperature controlled water bath $(298.00 \pm 0.01 \mathrm{~K})$. All systems contained 8-10 weight $\%$ of polymer (total composition). Both drying and equilibration procedures were confirmed with test samples.

12. Davidson, R. L. In Handbook of water-soluble gums and resins, McGraw-Hill: 1980.

13. Bartolotta A.; di Marco, D.; Lanza, M.; Carini, G.; Nuovo Cimento 1994, 16, 825.

14. Leo, A.; Hansch, C.; Elkins, D.; Chem. Rev. 1971, 71, 525.

15. Loh, W.; Beezer, A.E.; Mitchell, J.C.; Langmuir 1994, 10, 3431 and references therein.

16. Spitzer, M.; Sabadini. E.; Loh, W.; Abstracts of the XV Conference of the European Colloid and Interface Society, Coimbra, Portugal, 2001.

Received: June 12, 2001

Published on the web: December 5, 2001

FAPESP helped in meeting the publication costs of this article. 